\title{
GAS-LIQUID CHROMATOGRAPHY IN PHARMACOLOGY AND TOXICOLOGY
}

\author{
PHARMACOKINETIC ANALYSIS LIMITED BY THE SENSITIVITY OF THE \\ ANALYTICAL TECHNIQUE
}

J. M. van ROSSUM, D. D. BREIMER, G. A. M. vAN GINNEKEN, J. M. G. vAN KORDELAAR AND T. B. VREE

Department of Pharmacology, Catholic University Medical School, Nijmegen (The Netherlands)

SUMMARY

A survey is given conserving the possibility of gas-chromatographic analysis of drugs. Attention is paid to the plasma concentration curve, biological half-life and multicompartment kinetics.

The intensity of a drug-induced effect in man depends on the affinity to specific receptors and the concentration of such a chemical in the target tissue. This drug concentration in the receptor compartment is a function of the concentration in the blood or plasma.

Although in almost all cases the drug concentration in the target tissue cannot be assessed directly, the plasma concentration may be measured, provided that sensitive analytical techniques are available.

\section{The plasma concentration curve}

The concentration of a drug in the plasma is a time-dependent function of the dose administered. It is a reflection of what the body does to the drug, whereas the pharmacologic response is a reflection of what the drug does to the body.

As a rather extreme simplification, the human body may be considered as a single compartment into which a certain dose of a drug is introduced (Fig. I). By analogy, such a body compartment may be seen as a reservoir with a certain volume, which is continuously cleared at a certain rate by a water flow. Obviously, the initial concentration of a drug depends on the dose and the volume of distribution, while the elimination rate at any moment depends on the concentration at that moment and the clearance (flow).

In Fig. 2, plasma concentration curves are presented, following intravenous or oral administration of drugs in human subjects. The points are actual measurements, while the curves have been calculated under the assumption that the human body may be regarded as a single compartment. From the examples given, it may be 


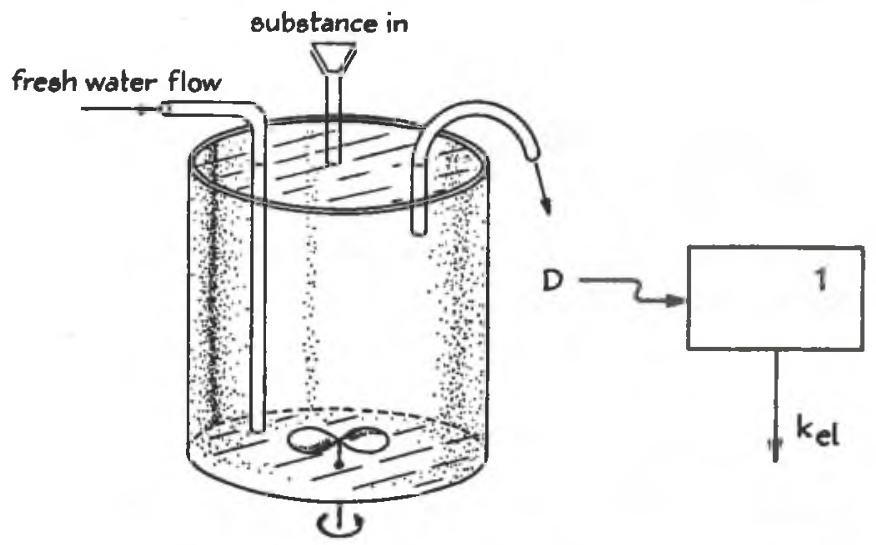

Fig. I. Model of the clearance of a substance from a reservoir with constant volume and a schematic presentation of a single compartment model. $\mathrm{D}=$ dose; $\mathrm{K}_{\mathrm{el}}=$ elim. clearance constant.
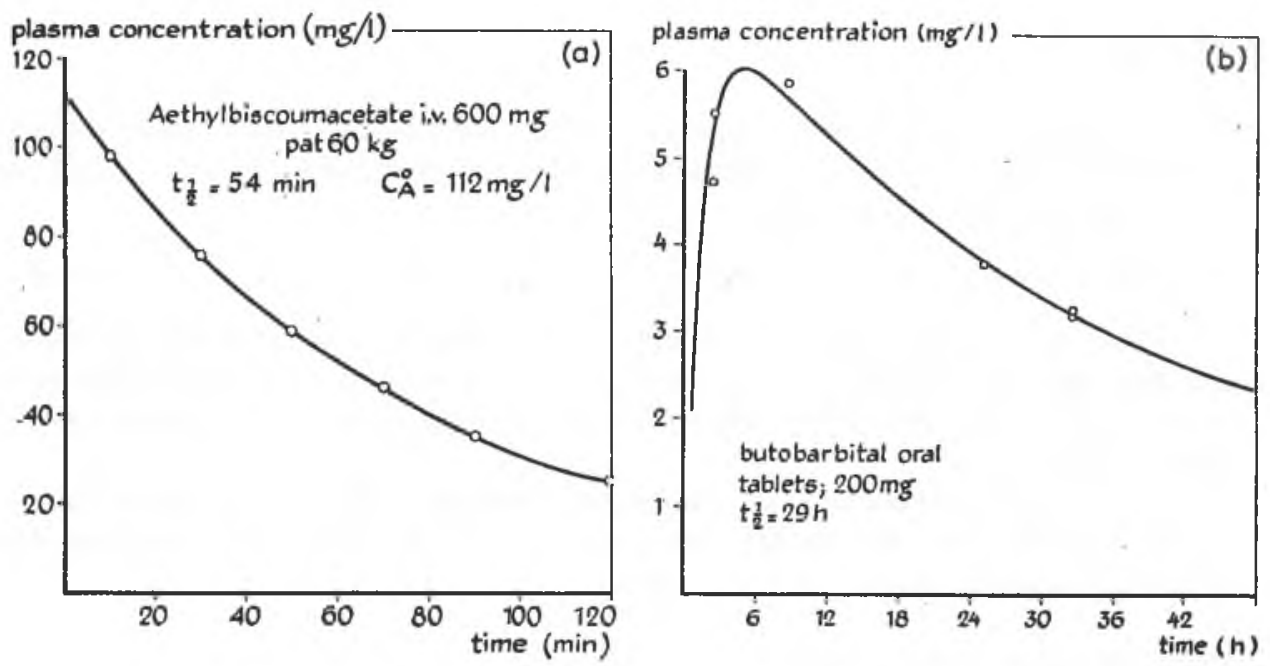

Fig. 2. Plasma concentration curves following: (a) i.v. administration of ethylbiscoumacetate (Tromexan) to a patient"; (b) oral administration of butobarbital to a test subject. The half-live calculated from the slope of the curve.

seen that relatively large doses were employed and that the time scale may be in minutes, hours or days: certain drugs disappear rapidly, whereas others remain in the body for a long period of time.

\section{Biological half-life and the fictive volume of distribution}

The rate at which a drug is eliminated from the body either by metabolism, excretion or both may be characterised by the half value time, $t \frac{1}{2}$. This time "constant" is defined as the period of time in which $50 \%$ of the drug is eliminated from the biological object. It has therefore been called the biological half-life. Obviously, the biological half-life will be larger if the volume of distribution is larger and the clearance constant is smaller. For a relationship see Table I. It may be noted from this table 
TABLE I

RELATIONSHip BeTWEen Elimination CLEaRANCE-CONSTANT $k_{e l}$, Volume of Distribution $V_{f}$ AND ELIMINATION-TIME-CONSTANT, $\tau_{e l}$, BIOLOGICAL-HALFLIFE, $t \frac{1}{2}$, AND ELIMINATION CONSTANT $r_{e l}$ Assuming that the human body may be regarded as a single-compartmental reservoir.

\begin{tabular}{|c|c|c|c|c|c|}
\hline Elimination process & $k_{e l}$ & $V_{f}$ & $t \frac{1}{2}$ & $\tau_{e l}$ & $\gamma_{e l}$ \\
\hline $\begin{array}{l}\text { Clearance equal to glome- } \\
\text { rular filtration from a } \\
\text { volume equal to the ex- } \\
\text { tracellular fluid }\end{array}$ & $\begin{array}{l}130 \mathrm{ml} / \mathrm{min} \\
7.8 \mathrm{l} / \mathrm{h}\end{array}$ & 121 & $I_{3} h_{m i n}$ & I h $32 \mathrm{~min}$ & $\begin{array}{c}0.0 \mathrm{Ir} / \mathrm{min} \\
0.65 / \mathrm{h}\end{array}$ \\
\hline $\begin{array}{l}\text { Clearance equal to urine } \\
\text { flow from a volume equal } \\
\text { to total body water }\end{array}$ & $\begin{array}{l}0.7 \mathrm{ml} / \mathrm{min} \\
42.0 \mathrm{ml} / \mathrm{h} \\
1.01 / \mathrm{d}\end{array}$ & 361 & $\begin{array}{r}576 \mathrm{~h} \\
25 \mathrm{~d}\end{array}$ & $\begin{array}{r}864 \mathrm{~h} \\
36 \mathrm{~d}\end{array}$ & $\begin{array}{r}0.0012 / \mathrm{h} \\
0.040 / \mathrm{d}\end{array}$ \\
\hline $\begin{array}{l}\text { Clearance equal to renal } \\
\text { plasma flow from a vol- } \\
\text { ume equal to total body } \\
\text { water }\end{array}$ & $\begin{array}{l}700.0 \mathrm{ml} / \mathrm{min} \\
42.0 \mathrm{l} / \mathrm{h}\end{array}$ & 361 & $35 \mathrm{~min}$ & $51 \mathrm{~min}$ & $\begin{array}{l}0.096 / \mathrm{min} \\
\mathrm{I.I} 7 / \mathrm{h}\end{array}$ \\
\hline $\begin{array}{l}\text { Clearance equal to liver } \\
\text { plasma flow from a vol- } \\
\text { ume equal to the plasma } \\
\text { volume }\end{array}$ & $\begin{array}{l}\text { I.0 } 1 / \mathrm{min} \\
60.0 \mathrm{l} / \mathrm{h}\end{array}$ & 31 & $2 \mathrm{~min}$ & $3 \mathrm{~min}$ & $\begin{array}{l}0.33 / \mathrm{min} \\
20.0 / \mathrm{h}\end{array}$ \\
\hline $\begin{array}{l}\text { Slow clearance from a } \\
\text { large fictive volume }\end{array}$ & $\begin{array}{l}2 \mathrm{ml} / \mathrm{min} \\
120 \mathrm{ml} / \mathrm{h}\end{array}$ & 3601 & $\begin{array}{r}2000 \mathrm{~h} \\
89 \mathrm{~d}\end{array}$ & $\begin{array}{r}3000 \mathrm{~h} \\
128 \mathrm{~d}\end{array}$ & $\begin{array}{r}0.00033 / h \\
0.0070 / d\end{array}$ \\
\hline $\begin{array}{l}\text { Fast clearance from a very } \\
\text { large fictive volume }\end{array}$ & $\begin{array}{l}120 \mathrm{ml} / \mathrm{min} \\
7.2 \mathrm{l} / \mathrm{h}\end{array}$ & 14401 & $\begin{aligned} 138 \mathrm{~h} \\
5.8 \mathrm{~d}\end{aligned}$ & $\begin{array}{l}200 \mathrm{~h} \\
8.3 \mathrm{~d}\end{array}$ & $\begin{array}{r}0.0050 / \mathrm{h} \\
0.12 / \mathrm{d}\end{array}$ \\
\hline
\end{tabular}

that the apparent volume of distribution may exceed the volume of the total body water. This is because the blood or plasma concentration is the reference point. So, if a drug is preferentially taken up in certain tissues, as e.g., muscle or fat, the concentration in such tissues may be $p$. times the concentration in the blood so that the apparent volume of that particular tissue is $p$. times the actual volume. On the other hand, if a drug binds firmly to plasma proteins the apparent volume of distribution may be very small.

The apparent volumes of distribution and the dose determine the concentration range in actual plasma which should be determined in order to make a study of the kinetic behaviour of a drug possible.

\section{Multicompartment kinetics}

When elimination from the body is slow with regard to absorption and distribution, the body may be regarded as a single compartment system. This is then likely the case for drugs with a very long half-life. For most drugs the situation is more complex or becomes more complex if the plasma curve is followed over a larger concentration range.

In general, the body may be seen as a number $(n)$ of compartments which are in exchange contact with the first or central compartment, the blood or plasma. The plasma concentration then may be described by the sum of a number of exponential terms:

$$
C_{t}=\sum_{i=1}^{n} A_{i} \cdot \mathrm{e}^{-t / r_{i}}
$$

Here, $C_{\mathrm{t}}$ is the concentration at a moment $t$ after administration of the drug. $A_{i}$ is the 


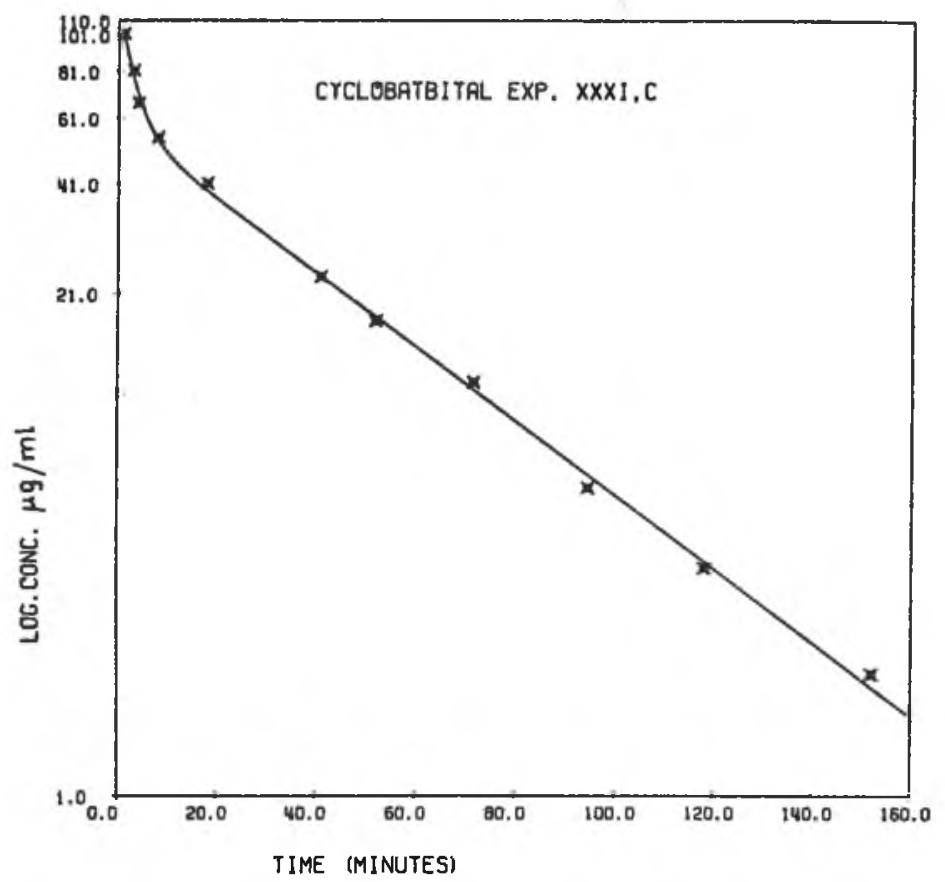

Fig. 3. Blood concentration curve of cyclobarbital in a rat, following i.v, administration. Note a biphasic decay curve.

$i$ th coefficient and $\tau_{i}$ the $i$ th time constant. Persistence in the body is thus no longer characterised by the biological half-life or a single time constant, but by a number of time constants.

In Fig. 3a blood concentration curve of cyclobarbital is given which has been determined in a single rat. The curve has been plotted through the measured points on basis of a two-compartment model.

In general, the elimination clearance constant $k_{e l}$ may easily be calculated if the entire curve is analysed:

$$
k_{e l}=D \cdot F / \sum_{i=1}^{n} A_{i} \cdot \tau_{i}
$$

Here $D$ is the dose of the drug and $F$ the biological availability or the fraction of the dose that ultimately will be absorbed (in case of parenteral administration $F=\mathbf{r}$ ).

It is evident that the entire plasma curve has to be determined in order to calculate the clearance constant with sufficient accuracy. It is obvious that the largest product $A_{i} \cdot \tau_{i}$ has the greatest influence on $k_{e l}$. This may be due mainly to a very large $A_{i}$ or a very large $\tau_{i}$, or both.

\section{Kinetics of drug metabolism}

Most drugs are transformed in the body into several metabolites, some of which may be pharmacologically active. It is therefore not only important to have some knowledge of the kinetics of the drug or toxic agent proper, but also of its active metabolites. 
A particular metabolite may be cleared at a higher rate than the parent compound and has a smaller fictive volume of distribution. The biological half-life of that metabolite is then smaller. Because of the smaller volume of distribution, relatively high concentrations may be found. This means that if reasonable concentrations of a metaloolite are found, such a substance need not be of importance.

On the other hand the half-life of a metabolite may be longer than that of the parent compound either because the clearance is smaller or the apparent volume of distribution is larger. Such a situation occurs for e.g. acetosal ( $t \frac{1}{2}=20 \mathrm{~min}$ ) (aspirine) that is rapidly converted into salicylic acid $\left(t \frac{1}{2}=5-6 \mathrm{~h}\right)$, while both parent drug and metabolite have a similar volume of distribution of 9-II l (Fig. 4).

Similar situations hold for certain psychotropic drugs, as imipramine $\left(t \frac{1}{2}=3 \mathrm{~h}\right)$ that is converted in desipramine ( $t \frac{1}{2}=$ approx. $36 \mathrm{~h}$ ) and diazepam $\left(t \frac{1}{2}=\right.$ approx. Io $\left.\mathrm{h}\right)$ that is converted into desmethyldiazepam ( $t \frac{1}{2}=$ approx. 2 days). The active metabollites formed have structures strongly related to the parent drug. This implies that the analytical technique employed should be selective for each substance and preferably be carried out in a similar way.
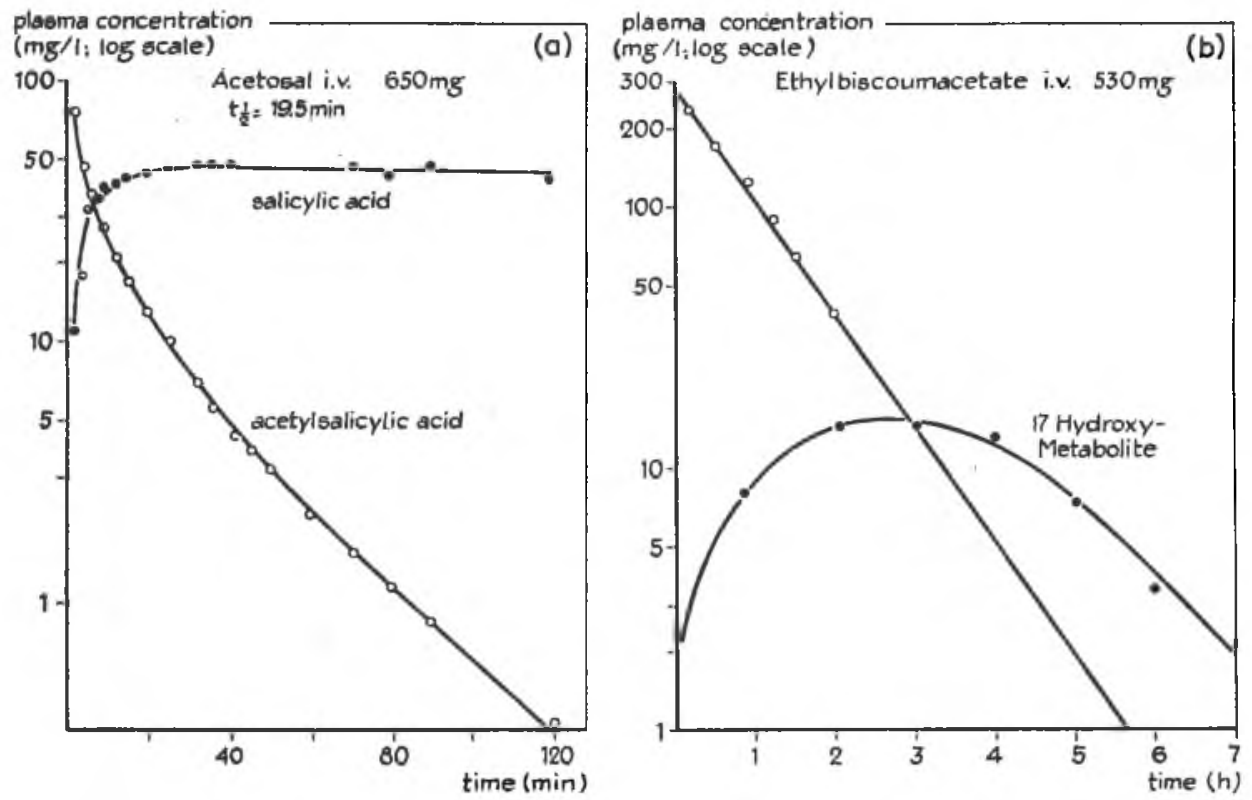

Fig. 4. (a) Plasma concentration curve of acetosal and its metabolite salicylic acid in a human; half-life of the parent drug and of the metabolite 5 . (b) Plasma curves of Tromexan and its hydroxymetabolite.

\section{Gas-liquid chromatography in pharmacokinetics}

As pointed out before, pharmacokinetic parameters may be determined with sufficient accuracy if the entire plasma concentration curve can be measured. This implies that a fairly large number of blood samples should be analysed while the sample size should be kept small (no more than $5 \mathrm{ml}$ in man and less than $0.2 \mathrm{ml}$ in rats). As a consequence of the formation of metabolites of related structure and prop- 
erties in the same sample, such metabolites should be determined also quantitatively. Except for those drugs that are administered in quantities of the order of grams, the concentration range in plasma is low (1o $\mu \mathrm{g} / \mathrm{ml}$ and far less). Therefore, highly sensitive analytical techniques have to be employed. The gas-liquid chromatographic techniques using the proper column filling and the proper detector, are rather ideal for this purpose.

(a) GLC with flame ionisation detection ( $\mu g$ quantities). For a number of drugs this method is excellent. Choosing a good column, carrier gas and oven temperature, a large number of samples may be analysed in a short time. The retention time should be short enough to assure sufficiently high sensitivity and rapid analysis (dose 100-500 $\mathrm{mg})$.

For most barbiturates (see Street, this symposium), this method gives very good results. Drugs given in much smaller quantities can not be analysed in most cases, unless their volume of distribution is very small. For instance, amphetamine and diazepam given in 5-25 mg quantities while their volume of distribution is more than $200 \mathrm{l}$, cannot be determined with the flame ionisation detector. This detector is not selective, so that in some cases, products normally present in the blood may interfere.

(b) GLC with a nitrogen detector (ng quantities). Detectors are available that are specifically sensitive to substances containing nitrogen action. The selectivity and

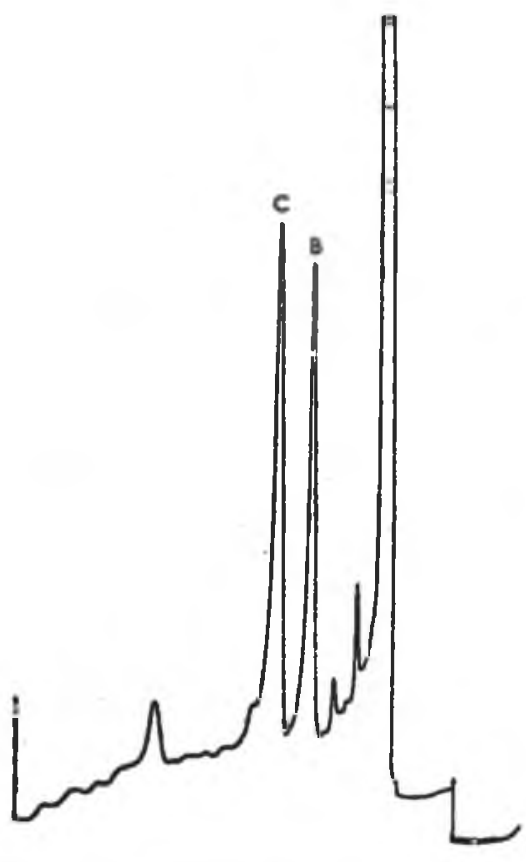

a

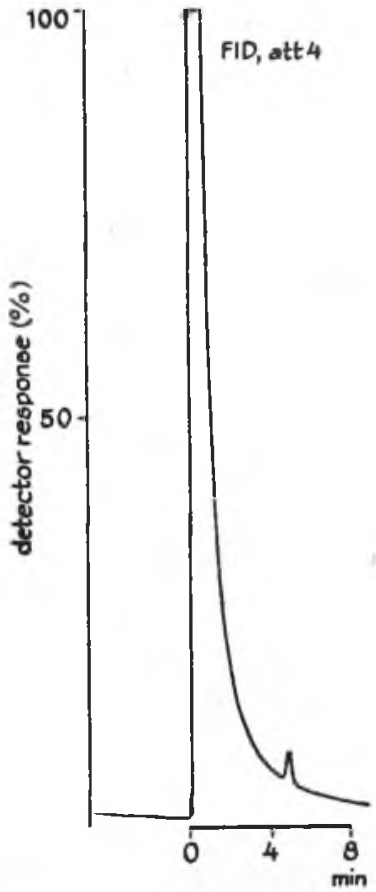

b
$E C D$,att 16

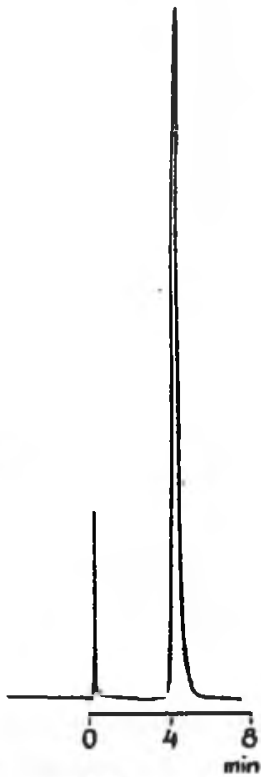

c

Fig. 5. (a) Gas chromatogram by using electron capture detector of chlorpheniramine (B, $4.9 \mathrm{mg}$ ) added to the sample and of brompheniramine (C) in blood of a subject receiving $8 \mathrm{mg} .{ }^{2}$ (b) Gas chromatogram of lynestrenol heptafluorobutyrate, using flame ionisation detector. (c) Electron capture detector. Note the large difference in sensitivity. 
sensitivity are greater than those of the flame ionisation detector. The method may be applied to amines and various other bioactive substances'.

(c) GLC with electron capture detector (ng-pg quantities). For drugs that contain halogen atonis as in the of case chlorpheniramine, the electron capture detector may be used (lig. 5). Sensitivity is then increased by a factor Io-IO0, so that the concentration of chlorpheniramine (duse 4-12 mg) in the blood may easily be measured?

For drugs that do not contain halogen or nitro moieties, such moieties have to be introduced by quantitative synthesis. Heptafluorobutyric acid and related substances are frequently used as coupling agents ${ }^{2}$. See Fig. 5 for a lynestrenol derivative.
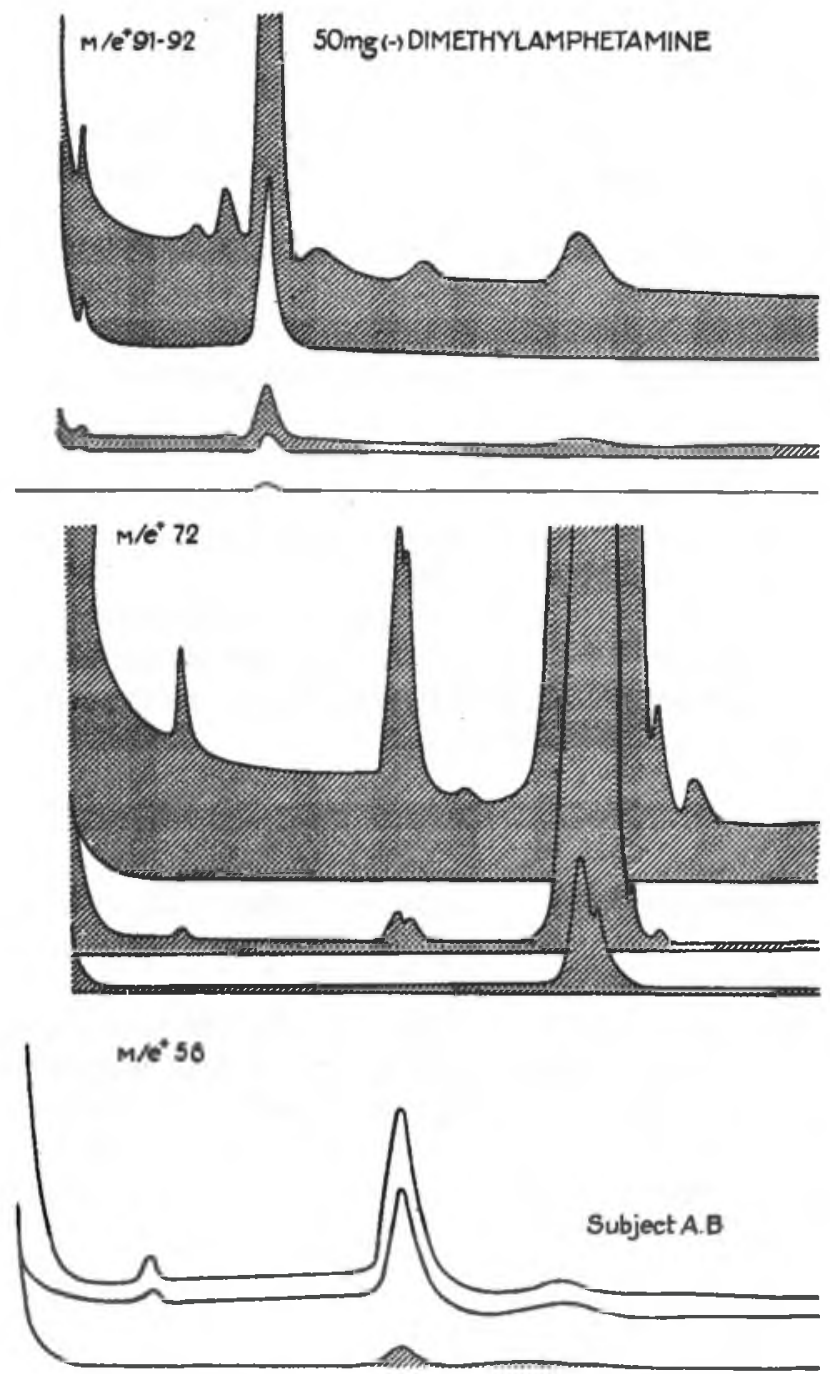

Fig. 6. Mass-fragmentograms of dimethylamphetamine and its metabolites in the urine of a subject who received dimethylamphetamine. Above: reference compound; middle: characteristic mass fragment 72 of dimethylamphetamine; below: characteristic mass fragment 58 of the metabolite methamphetamine. 
A disadvantage of the electron capture detector is that no large quantity of samples can be handled as the detector is easily poisoned. Furthermore, quantitative coupling procedures have to be devised for every drug and metabolite that has to be analysed.

(d) Mass-fragmentography. A mass spectrometer coupled to a gas chromatograph may be used as a detector. (See Brooks, this symposium.) The intensity of certain mass lines can be used as a measure for the amount of a drug. The method is, dependent on the mass spectrum, more sensitive than flame-ionisation detection and very selective. The method can easily be used for related compounds. For instance, a drug and its derivative in which one or more $\mathrm{H}$-atoms are replaced by deuterium, may be studied at the same time. In Fig. 6 mass-fragmentograms are given for dimethylamphetamine and its metabolites in the urine of a subject to whom the drug was administered via the oral route.

This method may also be used to determine the recovery of the extraction and purification procedures by adding to the sample an analogue in which deuterium is substituted for hydrogen.

(e) GLC and a detector for radioactive labels. A great problem in the analysis of minute amounts of drugs in body fluids is that the purification procedure leads to variable losses. This may be controlled by adding a small amount of a highly specific radioactive labeled drug to the plasma, so that the recovery of the procedure can be checked.

\section{Pharmacokinetic analysis by indirect methods}

There are many drugs which are very difficult to determine in plasma, if very low doses are given and the volume of distribution is large.

(a) Urinary excretion data. Information on the biological half-life may be obtained indirectly by measuring the urinary excretion rate instead of the plasma disappearance rate. The renal excretion rate is directly proportional to the plasma concentration if certain restrictions are fulfilled. In formula:

$$
\frac{\mathrm{d} Q r}{\mathrm{~d} t}=k_{r} C
$$

Where $\mathrm{d} Q_{r} / \mathrm{d} t$ is the renal excretion rate and $k_{r}$ is the renal clearance. The quantity excreted in the urine over a period of time may be larger by several factors than the quantity in a few ml of blood (Fig. 7).

(b) The plateau concentration following chronic administration. Chronic administration of a drug may result in accumulation if per unit of time more drug is absorbed than is eliminated. As a result, concentration may increase considerably. However, after a sufficiently long period of time, the concentration does not increase further and a plateau is reached. The concentration in the accumulation plateau is a simple relation to the dose and the dosage interval $(\delta \Delta t)$ :

$$
\bar{C}_{p l}=D \cdot F / \Delta t \cdot k_{s l}
$$

Therefore, without following the entire plasma curve, the clearance constant may be determined directly from the concentration in the plateau. Since this concentration is much higher than the maximum of the curve following a single dose, accumulation plateau concentrations may be studied initially. 

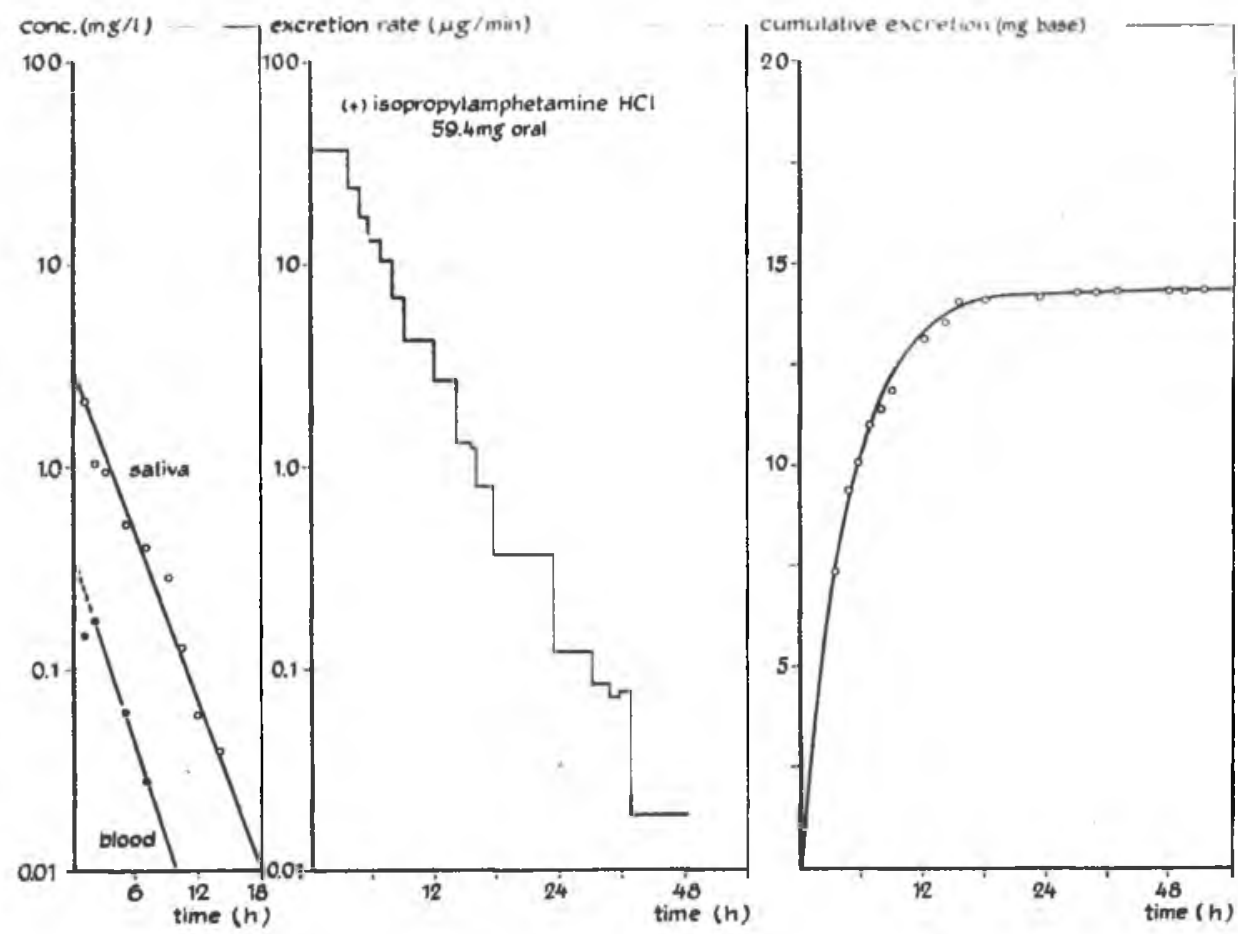

Fig. 7. Blood concentration curve of isopropyl-amphetamine in a human subject simultaneously with the concentration in the saliva, which is almost ro times higher, and the renal excretion rate curve. Note that the curves run parallel so that the biological half-life may be calculated from the urinary data alone.

\section{Conclusions}

Blood and tissue concentrations of most drugs may be determined with GLC procedures.

In addition to the use of the flame ionisation detector and columns of a size normal for drugs given in reasonable doses (I00-1000 $\mathrm{mg}$ ), the combined GLC-mass spectrometry may, be of extremely great help for the rapid and selective analysis of minute quantities of drugs and their metabolites.

The extraction and purification procedures prior to GLC separation in general set a limit to the sensitivity, unless recovery can be brought under control.

\section{REFERENCES}

I M. von Donikr, Sportartz und Sportmedizin, 21 (1970) 27.

2 R. B. Bruce, J. E. Pitts and F. M. Pinchbeck, Anal. Chem., 40 (I968) 1246.

3 T. While and H. Ehrsson, Acta Pharmacol. Suecica, 7 (1970) 389.

4 F. E. vaN DAM, Thesis, University of Nijmegen, Thoben-Offset, Nijmegen, The Netherlands, I968.

5 M. Rowland, S. Rirgriman, P. A. Harris, S. D. Sholkoff and E. J. Eyring, Nature, $2 r_{5}$ (1967) 413 . 